\title{
Pneumatosis intestinalis with complete remission: a case report
} \section{Aly Saber}

Address: Department of general surgery, Port-Fouad General Hospital, Al-obour street- Port-Fouad, 11361, Egypt

Email: alysaber@hotmail.com

Published: 29 April 2009

Received: 2 January 2009

Cases Journal 2009, 2:7079 doi: 10.1186/1757-1626-2-7079

Accepted: 19 February 2009

This article is available from: http://casesjournal.com/casesjournal/article/view/2/4/7079

(C) 2009 Saber; licensee Cases Network Ltd.

This is an Open Access article distributed under the terms of the Creative Commons Attribution License (http://creativecommons.org/licenses/by/3.0), which permits unrestricted use, distribution, and reproduction in any medium, provided the original work is properly cited.

\begin{abstract}
Introduction: Pneumatosis cystoides intestinalis is a rare disease characterized by presence of multilocular cysts in the gastrointestinal wall. Rarely, patients may experience symptoms secondary to the cysts. The pathogenesis of pneumatosis cystoides intestinalis is still unclear and many theories have been advocated to explain the exact origin. Complications occur in about $3 \%$ of cases and include obstruction, intussusception, volvulus, haemorrhage and intestinal perforation.

Case presentation: The author reported a male patient aged 56 years presented to the emergency department with acute upper abdominal pain. Widespread variable sized serosal intestinal air cysts were seen at the first look involving long segment of jejunum and ileum. Perforated duodenal ulcer, as the cause of generalized peritonitis, was repaired with direct closure and omental patch. A second laparotomy, was done and exploration was systematically performed and denoted hugely distended stomach with cicatrisation at the site of previous closure of perforated duodenal ulcer and the whole length of small gut was completely free from the already described pneumatosis cystoides intestinalis.
\end{abstract}

Conclusion: The pneumatosis cystoides intestinalis is a rare disease and suspicion of this disease process should be based on imaging and clinical finding. The therapy can be conservative or surgical in restricted situations.

\section{Introduction}

Pneumatosis cystoides intestinalis is a rare disease characterized by presence of multilocular cysts in the gastrointestinal wall. Idiopathic and secondary forms of the disease can be distinguished [1]. In the primary idiopathic form, multiple thin-walled cysts develop in the submucosa or subserosa of the gut. Usually, this form has no associated symptoms, and the cysts may be found incidentally through radiography or endoscopy [2]. The secondary form (85\% of cases) is associated with obstructive pulmonary disease, as well as with obstructive and necrotic gastrointestinal disease $[1,2]$.

Primary pneumatosis is often asymptomatic. Rarely, patients may experience symptoms secondary to the cysts. Signs and symptoms include diarrhea, bloody stools, abdominal pain, abdominal distention, and constipation. The physical findings are usually unremarkable [3]. 
Pneumatosis cystoides intestinalis may be associated with bowel ischemia, perforation, and a high mortality rate. As a result, many authorities advocate an aggressive surgical approach in those patients [4].

The pathogenesis of pneumatosis cystoides intestinalis is still unclear and many theories have been advocated to explain the exact origin [5-7]. The mechanical theory, which is the most accepted explanation and suggests that gas under pressure, is forced into the bowel wall through a mucosal defect associated with trauma, surgery, endoscopy and bowel obstruction $[5,7]$.

Second, there is the bacterial theory. In animal experiments, introduction of bacteria into the bowel wall by injection has been shown to cause PCI [8]. The pulmonary theory has been criticized as the assumption that gas travels from ruptured alveoli through the mediastinum into retroperitoneal space and finds its way along perivascular spaces through the mesentery into the bowel wall could not be proven convincingly [7].

Complications occur in about 3\% of cases and include obstruction, intussusception, volvulus, haemorrhage and intestinal perforation $[5,6]$.

\section{Case presentation}

A fit and otherwise healthy male patient aged 56 years from the Asian part of Egypt, presented to the emergency department with acute upper abdominal pain with three hours duration. The patient was in agony with anxious look. Due to religious background, he did not drink alcoholic beverages. His body temperature was $37.7^{\circ} \mathrm{C}$ and pulse rate was 88 beats per minute. Abdominal examination revealed tenderness over the epigasrtic region and the right side of the abdomen with rigidity maximally detected all over the right abdomen.

Plain x-ray films detected free gas under the diaphragm and abdomino-pelvic ultrasonography demonstrated free fluid in the peritoneal cavity.

After the routine work up and proper resuscitation, laparotomy was performed. Widespread variable sized serosal intestinal air cysts were seen at the first look involving long segment of jejunum and ileum. All cysts were intact and were not incriminated as a cause of pneumoperitoneun or peritonitis (Figure 1). Perforated duodenal ulcer, as the cause of generalized peritonitis, was repaired with direct closure and omental patch. Nothing was done for the intestinal air cysts. Metronidazol intravenous infusion was given two times daily.

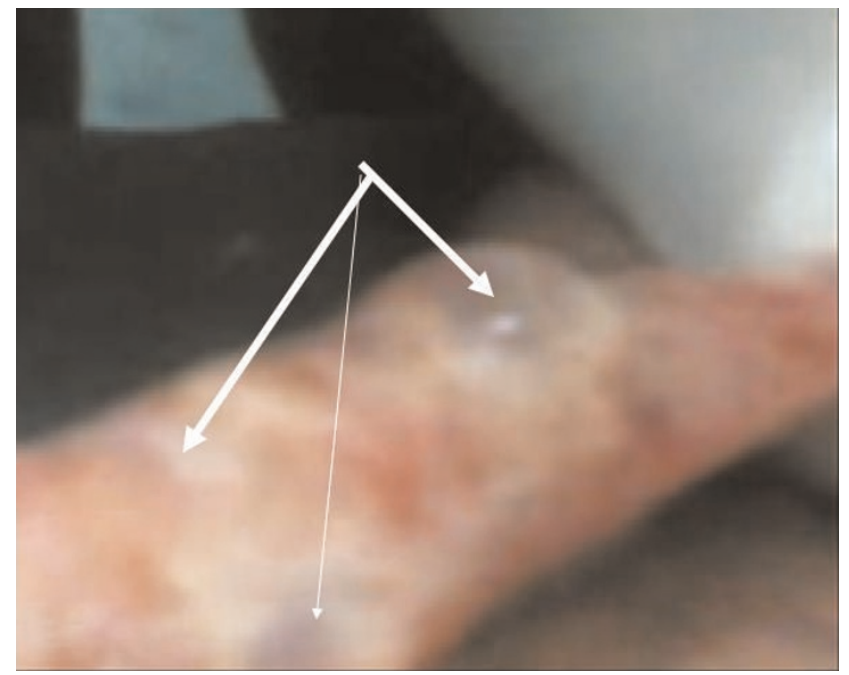

Figure I.

A photograph showing widespread variable sized serosal intestinal air cysts involving long segment of jejunum and ileum. All cysts were intact and were not incriminated as a cause of pneumoperitoneun or peritonitis.

The patient passed very smooth postoperative course and was followed up for the next eight months until the complaint of repeated vomiting was evident and food particles of eaten diets since more than two days were recognized in the vomitus.

Upper gastro-duodenal endoscope and barium meal study were performed and revealed gastric outlet obstruction. Computed axial tomography also confirmed the diagnosis and denied any other pathology.

Laparotomy, through the previous midline incision, was done and exploration was systematically performed and denoted hugely distended stomach with cicatrisation at the site of previous closure of perforated duodenal ulcer and the whole length of small gut was completely free from the already described pneumatosis cystoides intestinalis (Figure 2). Gastro-jejunostomy with truncal vagotomy were done to bypass the outlet obstruction.

\section{Discussion}

Pneumatosis cystoides intestinalis is a rare disease and the exact cause is probably a combination of associated diseases causing elevated pressure and mucosal damage allowing gas-forming microorganisms to enter the bowel wall, thus forming the cysts [9]. 


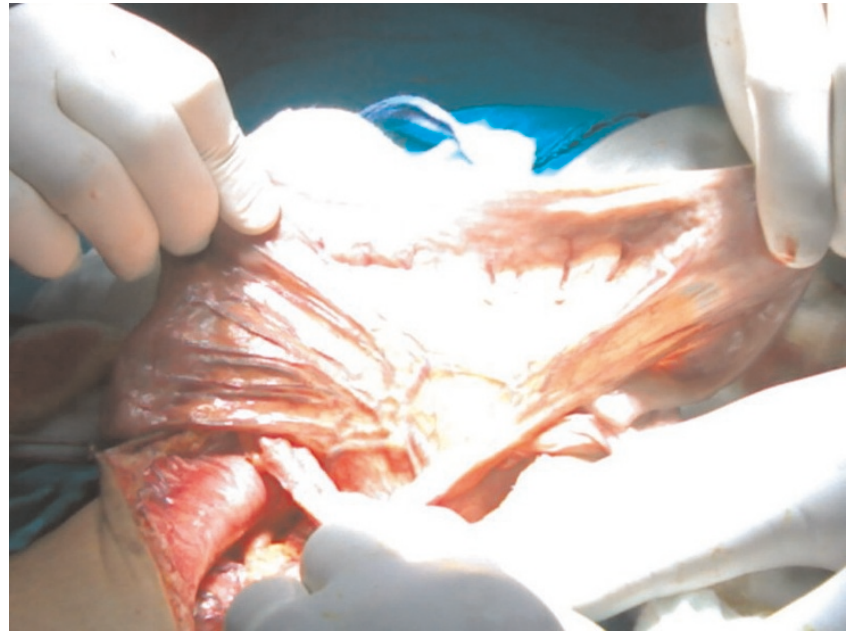

Figure 2.

A photograph showing the whole length of small gut completely free from the already described pneumatosis cystoides intestinalis.

The author in this case report put the question whether pneumatosis cystoides intestinalis is the direct cause of perforated duodenal ulcer or the result of this disease process as advocated in other pervious reports $[10,11]$.

Previous data stated that the cysts may be located in the subserosa, submucosa, and, rarely, the muscularis layer $[1,4]$. They may be single or multiple and vary in size from microscopic to several centimeters in diameter [4]. They are usually lined by mixed inflammatory cells, macrophages, or foreign body giant cells [12]. In the present case, the author found that the cysts were completely located in the subserous plane with varying sizes and shapes.

Usually, no treatment is necessary for $85 \%$ of patients who are asymptomatic. The resolution of gas collections has been reported after inhalation of $70 \%$ of oxygen and after hyperbaric oxygen therapy $[4,9,13]$ Good results can be achieved in most cases by conservative means, but surgical treatment may be necessary in some cases [13]. Surgery should be avoided unless there are signs of severe inflammation, metabolic acidosis or portal venous gas, which are indicators of more serious diseases $[13,14]$.

In the post-operative period, the patient of the present case was given metronidazole $500 \mathrm{mg} / 12$ hour as intravenous infusion together with cefotaxim $1 \mathrm{gm} / 8$ hour. We noticed that the cysts showed complete resolution during the second operation with no adhesion formation or amalgamation between the intestinal loops. This finding came in agreement with those data reporting that therapy with metronidazole up to $1500 \mathrm{mg}$ daily was effective to cause resolution of pneumatosis cystoides intestinalis [15-17].

\section{Conclusion}

The pneumatosis cystoides intestinalis is a rare disease and suspicion of this disease process should be based on imaging and clinical finding. The therapy can be conservative or surgical in restricted situations.

\section{Consent}

Written informed consent was obtained from the patient for publication of this case report and accompanying images. A copy of the written consent is available for review by the Editor-in-Chief of this journal.

\section{Competing interests}

The author declares that he has no competing interests.

\section{Acknowledgements}

The author would to thank his colleague and assistant Dr, Yasser Abou-Zeid for his co-operation that makes this work possible. The author would appreciate the efforts of Mrs. Mervat Kamel for her help in writing, preparing software of figures and editing the thesis.

\section{References}

I. Voboril R: Pneumatosis cystoides intestinalis-a review. Acta Medica (Hradec Kralove) 2001, 44(3):89-92.

2. Theisen J, Juhnke P, Stein HJ et al.: Pneumatosis cystoides intestinalis coli. Surg Endosc 2003, I 7(I): I57-158.

3. Greenstein AJ, Nguyen SQ, Berlin A et al.: Pneumatosis intestinalis in adults: management, surgical indications, and risk factors for mortality. J Gastrointest Surg 2007, I I (I 0): | 268- I 274.

4. Tchabo NE, Grobmyer SR, Jarnagin WR, Chi DS: Conservative management of pneumatosis intestinalis. Gynecol Oncol 2005, 99(3):782-784. Epub 2005 Sep 19

5. Zorcolo L, Capra F, D'Alia G et al.: Pneumatosis cystoides of the right colon: a possible source of misdiagnosis. Report of a case. Chir ltal 2005, 57(I): I 2 I- I 26.

6. Zimoch R: Pneumatosis coli complicated with necrosis and perforation wall of sigmoid colon and diffuse peritonitis. Pol Arch Med Wewn 2006, I I5(4):36I-365.

7. Boerner RM, Fried DB, Warshauer DM, Isaacs K: Pneumatosis intestinalis: two case reports and a retrospective review of the literature from 1985 to 1995. Dig Dis Sci 1996, 41:2272-2285.

8. Yale $C E$, Balish $E$ : The natural course of clostridium perfringens-induced pneumatosis cystoides intestinalis. J Med 1992, 23:279-288.

9. Rennenberg RJ, Koek GH, Van Hootegem P, Stockbrügger RW: Pneumatosis cystoides intestinalis, four cases of a rare disease. Neth J Med 2002, 60(I):22-25.

10. Muyembe VM: Pneumatosis cystoides intestinalis associated with ascites and pyloric stenosis secondary to a chronic duodenal ulcer: case report. East Afr Med J 2002, 79(I 2):667-668.

II. Ağaoğlu N: Pneumatosis cystoides intestinalis associated with perforated chronic duodenal ulcer and Meckel's diverticulum. Acta Chir Belg 2005, I05(4):4I5-4I7.

12. Solorzano J, Bhatt S, Dogra VS: Pneumatosis Intestinalis of the Sigmoid Colon Secondary to Repetitive Injury to the Rectum From the Insertion of Foreign Bodies. Appl Radiol 2007, 36(8).

13. Mclaughlin SA, Nguyen $\mathrm{JH}$ : Conservative management of nongangrenous esophageal and gastric pneumatosis. Am Surg 2007, 73(9):862-864. 
14. St Peter SD, Abbas MA: The spectrum of pneumatosis intestinalis. Arch Surg 2003, 138:68-75.

15. Tak PP, Van Duinen CM, Bun P, Eulderink F, Kreuning J, Gooszen HG, Lamers CB: Pneumatosis cystoides intestinalis in intestinal pseudoobstruction. Resolution after therapy with metronidazole. Dig Dis Sci 1992, 37(6):949-954.

16. Vetter Ch, Bonél H, Robert-Tissot L, Bielecki WJ: Pneumatosis cystoides intestinalis: a rare illness in adults. Praxis (Bern 1994) 14 2007, 96(46): 1815-1820.

17. Jauhonen P, Lehtola J, Karttunen T: ITreatment of pneumatosis coli with metronidazole. Endoscopic follow-up of one case. Dis Colon Rectum 1987, 30(10):800.

\section{Additional file}

A video screen showing widespread variable sized serosal intestinal air cysts involving long segment of jejunum and ileum. All cysts were intact.

\section{Do you have a case to share?}

Submit your case report today

- Rapid peer review

- Fast publication

- PubMed indexing

- Inclusion in Cases Database

Any patient, any case, can teach us something

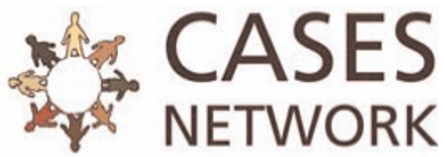

www.casesnetwork.com 